\title{
Análise do currículo referência de Química de uma rede estadual de Educação
}

\section{Analysis of the reference curriculum of Chemistry of a State Education system}

Ricardo Silvério Gomes Pinheiro $^{1}$. Marlúcio Tavares do Nascimento ${ }^{1}$

\begin{abstract}
Resumo: O Currículo de Referência do Sistema de Educação do Estado de Goiás originou-se do documento "Pacto pela Educação" publicado pela Secretaria de Educação de Goiás, estabelecendo como objetivo a definição de currículo mínimo para o Ensino Básico. Este é um trabalho que apresenta uma análise do Currículo Referência de Química, demonstrando sua afinidade com as Diretrizes Curriculares Nacionais para Educação Básica, com os Parâmetros Curriculares Nacionais para o Ensino Médio de Ciências da Natureza e com o perfil curricular elaborado pelos autores Jonnaert, Ettayebi e Defise. As análises demonstram que o currículo de Química é um programa de ensino com várias fragilidades que contradizem o discurso de sua proposta.
\end{abstract}

Palavras-chave: Currículo. Ensino de química. Ensino básico. Análise. Contextualização.

\begin{abstract}
The Reference Curriculum of State Education System of Goiás originated from the document "Pact for Education", published by the Secretary of Education of Goiás, establishing as a goal the definition of a "minimum curriculum" for the Basic Education and High School. This work presents an analysis of the Reference Curriculum of Chemistry, demonstrating its affinity with the National Curricular Guidelines for Basic Education and High School, with the National Curricular Parameters for High School of Natural Sciences and with the curricular profile by authors Jonnaert, Ettayebi and Defise. The analyses show that the Chemistry curriculum is a teaching program with several fragilities that contradict the discourse of its proposal.
\end{abstract}

Keywords: Curriculum. Chemistry teaching. Basic education. Analysis. Contextualization.

\footnotetext{
${ }^{1}$ Instituto Federal Goiano, Iporá, GO, Brasil. E-mail: <ricardo.silverio@ifgoiano.edu.br>.
} 


\section{Introdução}

Em setembro de 2011, a Secretaria de Estado de Educação, Cultura e Esporte de Goiás (SEDUCE) lançou um programa que prometia uma reformulação na educação goiana, denominado Diretrizes do Pacto pela Educação - Reforma Educacional Goiana. Um dos pilares do programa é a adoção de práticas de ensino que culminariam em grandes melhorias para a aprendizagem, sendo fruto disso a construção de um Currículo Referência.

O currículo no meio educacional é entendido, muitas vezes, como uma lista de conteúdos escolares e objetivos que se esperam alcançar com o ensino dos mesmos, sendo, portanto, um programa de ensino com características inflexíveis que pouco contribui para sua execução de forma contextualizada e interdisciplinar. Baseado nisso, Libâneo (2011) aponta, ao analisar o programa Pacto pela Educação do Estado de Goiás, algumas propostas curriculares que se alinham à criação de programas de ensino, como: a retirada da autonomia do professor para elaboração de seu plano de ensino, tornando-o assim um professor-tarefeiro; proposta de kits de habilidades práticas prontos; nivelamento de conteúdo alinhado à pedagogia comportamental tecnicista e foco no cumprimento de metas, que são apresentadas posteriormente no Currículo Referência na forma de bimestralizações a serem cumpridas. Considerando as críticas de Libâneo (2011), o que se vê no Currículo Referência é um quadro congestionado de conteúdos que devem ser ensinados em tempo limitado, exigindo simultaneamente que seja oferecida uma formação integral ao estudante. Essa é uma problemática ligada diretamente à pouca ou quase nenhuma flexibilidade e adaptação curricular, o que dificulta o trabalho docente pela estrutura rígida e imutável que, muitas vezes, o currículo apresenta.

Neste trabalho apresenta-se a descrição do Currículo Referência de Química da Rede Estadual de Educação de Goiás e a análise do documento com base nas Diretrizes Curriculares Nacionais para Educação Básica (DCN); nos Parâmetros Curriculares Nacionais para o Ensino Médio (PCNEM) de ciências da natureza, e no perfil curricular proposto por Jonnaert, Ettayebi e Defise (2010). No Currículo Referência de Química foram analisados diversos aspectos, desde a estrutura organizacional até a essência dos conteúdos e objetivos. Procurou-se sempre responder às seguintes perguntas: Quais os aspectos apresentados pelo Currículo Referência da Rede Estadual de Educação de Goiás a respeito da contextualização, interdisciplinaridade e flexibilidade? Há coerência nos discursos expressos no Currículo Referência de Química da Rede Estadual de Goiás em comparação com os discursos expressos nos documentos curriculares norteadores do currículo a nível nacional?

\section{Currículo: história, significados e perfil curricular}

Segundo Silva (2006, p. 4820, grifo do autor), “curriculum significa caminho, trajeto, percurso, pista ou circuito atlético". A concepção de currículo é muito ampla, tendo suas primeiras ideias desenvolvidas no século XVI, com a introdução da pedagogia de classes, superando a forma de educação do sistema feudal (em que o ensino era baseado na instrução individualizada, ou seja, os estudantes eram ensinados um de cada vez, prevalecendo a ordem dos fatos como a ideia de eficácia do processo). No sistema de classes, o diploma ou título era concedido a quem completasse o curriculum estabelecido, sendo uma forma de premiação atribuída quando chegasse ao fim do percurso, que era o mesmo estabelecido para todas as classes escolares 
(SILVA, 2006). Nesse contexto (passagem da Idade Média para Idade Moderna), a pedagogia de classes foi inserida de forma a superar a instrução individualizada, vindo atender interesses do mercado de trabalho (mercantilismo). Distinguia-se em classes de escolarização avançada, para aqueles que podiam pagar mais por esta e, em classes de escolarização para os pobres da zona rural, cuja educação se pautava em aspectos religiosos e virtudes seculares (HAMILTON, 1980 apud GOODSON, 2013, p. 32-33).

No período da Idade Moderna, a pedagogia de classes foi superada pelo que conhecemos por pedagogia de sala de aula, surgindo formas diferenciadas para a organização curricular, bem como para a matéria escolar e aulas compartimentalizadas. Surge a fragmentação dos saberes, onde tudo começa a ser avaliado por partes, como a ideia de que cada parte é responsável por gerar um conhecimento examinável. As avaliações tinham o objetivo de demonstrar o quanto uma matéria era apreendida pelos estudantes, sendo um meio de dar importância maior àquele conhecimento avaliado. Tinha-se nesse novo sistema pautado pela trilogia até atualmente conhecida: pedagogia, currículo e avaliação. Isso é evidente nos dias de hoje quando muitas das vezes currículo e matéria escolar são tratados como sinônimos e os exames avaliativos tem um papel de maior destaque (GOODSON, 2013). O processo de avaliação por matéria escolar disseminou na sociedade a ideia do conhecimento acadêmico mais restrito e distante de um contexto mais amplo. Esse é um paradigma que perdura até os dias atuais, influenciando principalmente na adoção de políticas públicas que insistem em avaliar o processo educacional em partes, e não como um todo. Séculos mais tarde o currículo ganha mais espaço no contexto educacional por intermédio de um movimento iniciado nos Estados Unidos, ocorrido nos anos finais do século XIX e início do século XX. É nesse mesmo período que o movimento da Escola Nova ganha força, apoiando a teoria curricular em uma visão voltada às experiências de vida do estudante (JONNAERT; ETTAYEBI; DEFISE, 2010).

\section{Significação do currículo}

De acordo com Jonnaert, Ettayebi e Defise (2010), a corrente francófona, que é mais voltada à educação dita hoje tecnicista e alinhada à ideia da fragmentação dos saberes, trata o currículo como sinônimo de programa de ensino, sendo esta uma forma sistemática de organização dos saberes escolares, cujos objetivos são específicos de cada um. A corrente anglófona, de cunho escolanovista, trata o programa de ensino como parte do currículo, que é flexibilizado e adaptado para que haja integração entre os saberes e práticas sociais, valores, cultura etc. Neste, os objetivos estão engajados de forma a se tornarem a pretensão de um currículo todo, e não somente de uma de suas partes. É por isso que "a flexibilidade de um currículo é um dos elementos importantes de um sistema educativo se há interesse em que ele possa se adaptar às necessidades da sociedade em matéria de educação" (JONNAERT; ETTAYEBI; DEFISE, 2010, p. 22).

Ribeiro Júnior (2013) chamam atenção para a ressignificação do currículo, afirmando que quando se lhe atribui um significado, nega-se outro. Dessa forma, "quando atribuímos ao currículo o significado de artefato cultural, estamos negando-lhe os significados de objeto que uma vez produzido estaria pronto e acabado" (RIBEIRO JÚNIOR, 2013, p. 46). Um programa de ensino é um currículo pronto e acabado, com conteúdos delimitados e engessados. Sob uma perspectiva anglófona, o currículo é um artefato cultural e histórico, cujo processo de 
significação é dinâmico e holístico, ou seja, seus significados podem ser alterados e dependem de outros significados (RIBEIRO JÚNIOR, 2013).

Considerando-se estas concepções, defende-se neste trabalho a ideia de um currículo integral, como artefato cultural, que deve ser sempre ressignificado e flexível para que possa ser adaptado ao contexto em que se encontra inserido. Assim, acredita-se que é preciso ressignificar o currículo com base numa visão mais dinâmica, considerando a corrente anglófona de pensamento.

\section{Competências, interdisciplinaridade e contextualização}

As DCN estão pautadas por uma concepção que prevê a construção de um currículo integrado, que busca na interdisciplinaridade, transversalidade e contextualização formas de flexibilizar o conteúdo e promover sua real significação na vida cotidiana e na sociedade.

A interdisciplinaridade pressupõe a transferência de métodos de uma disciplina para outra. Ultrapassa-as, mas sua finalidade inscreve-se no estudo disciplinar. Pela abordagem interdisciplinar ocorre a transversalidade do conhecimento constitutivo de diferentes disciplinas, por meio da ação didático-pedagógica mediada pela pedagogia dos projetos temáticos. A transversalidade é entendida como forma de organizar o trabalho didáticopedagógico em que temas, eixos temáticos são integrados às disciplinas, às áreas ditas convencionais de forma a estarem presentes em todas elas. (BRASIL, 2013, p. 184).

A interdisciplinaridade não é uma junção de disciplinas, pois se assim fosse, o currículo estaria preso a uma ideia de grade curricular, focada somente em juntar os conteúdos como forma de interligá-los às disciplinas envolvidas (FAZENDA, 2008). Ela está voltada à forma como se dá essa interconexão entre as disciplinas. É por isso que a transversalidade voltada à ideia dos eixos temáticos permite interconectar as disciplinas dentro de um mesmo contexto. Amorim, Souza e Trópia (2009, p. 4) entendem a contextualização como meio de relacionar "[...] a teoria estudada em sala de aula com as vivenciadas no dia-a-dia do aluno", sendo então uma forma de permitir a visualização e a aplicação dos conhecimentos e, ao mesmo tempo, compreender a sua origem. Essa ligação entre interdisciplinaridade, transversalidade e contextualização são compreendidas como fatores integrados a um mesmo processo, em que "a contextualização e a interdisciplinaridade são explicitadas como eixos complementares ao fazer pedagógico, necessário para a discussão e transformação da sociedade" (AMORIM; SOUZA; TRÓPIA, 2009, p. 4).

Dentro dessa discussão curricular insere-se a conceituação de competências e habilidades. Jonnaert, Ettayebi e Defise (2010) apresentam um conceito amplo de competência, defendendo que ela está relacionada a três lógicas: curricular, construída e atuacionista. A primeira delas, a curricular, é aquela cuja competência já é pré-estabelecida como ocorre nos programas de ensino. A construída é voltada ao fato de o estudante desenvolver suas próprias competências. A atuacionista é aquela que se constrói pela ação, e, portanto, está relacionada à curricular e à construída, pois se trata de um tipo de competência desenvolvida com base no currículo pro- 
priamente dito, porém, levando em conta o contexto do estudante. Esta última competência é do tipo que ocorre por meio do processo de contextualização em que um programa de ensino é aproximado da realidade do sujeito e adaptado à mesma, apresentando-se como ações que visam uma formação integral. A competência diz respeito ao conjunto de saberes, informações e habilidades para execução de uma tarefa, enquanto que a habilidade está mais voltada a uma capacidade adquirida. Mas essa definição pode não ser tão precisa, já que, dependendo do contexto, a habilidade pode ser uma competência a ser desenvolvida (CARDOSO; HORA, 2013).

Os PCNEM definem competências e habilidades e trazem orientações que norteiam cada sistema de ensino a desenvolverem seus currículos. Eles se baseiam em três grandes domínios, se tratando de competências atuacionistas que buscam relação do conteúdo com o contexto do estudante. Isso fica explícito principalmente nos PCNEM de Ciências da Natureza, no que concerne à Química: "As competências e habilidades cognitivas e afetivas desenvolvidas no ensino de Química deverão capacitar os alunos a tomarem suas próprias decisões em situações problemáticas, contribuindo assim para o desenvolvimento do educando como pessoa humana e como cidadão" (BRASIL, 1999, p. 32).

Os PCNEM trazem a ideia de uma formação integral que foca na busca da autonomia do educando para a resolução de um problema. O problema é uma situação dentro de um contexto que interliga a Química às demais áreas do conhecimento. Pode ser um problema advindo de questões ligadas ao meio ambiente, à indústria, a atividades cotidianas etc. Isso fica mais uma vez explícito nos PCNEM quando colocam, por meio de um exemplo, que a poluição ambiental

[...] seja ela urbana ou rural, do solo, das águas ou do ar, não é algo só "biológico", só “físico" ou só "químico", pois o ambiente, poluído ou não, não cabe nas fronteiras de qualquer disciplina, exigindo, aliás, não somente as Ciências da Natureza, mas também as Ciências Humanas, se se pretender que a problemática efetivamente sócio-ambiental possa ser mais adequadamente equacionada, num exemplo da interdisciplinaridade imposta pela temática real. (BRASIL, 1999, p. 8).

O exemplo da poluição ambiental ultrapassa as fronteiras disciplinares, assumindo problemáticas interdisciplinares que criam uma interação entre a Química, Física, Biologia, História, Geografia e Sociologia. Porém, mais do que isso, engloba um contexto real. Esses aspectos, isto é, interdisciplinaridade e contextualização, asseguram a transversalidade que perpassa as áreas do conhecimento sob uma única problemática (BRASIL, 2013).

\section{O perfil curricular de Jonnaert, Ettayebi e Defise (2010)}

Jonnaert, Ettayebi e Defise (2010) definem seis características principais que um currículo deve apresentar para ter o mínimo de operacionalidade. São essas características: ser único, ser consensual, ser unívoco, ser flexível, ser coerente internamente e coerente externamente. Cada uma dessas características é avaliada em graus de 0 a 3. A unicidade (ser único) do currículo se refere ao fato de existir um ou mais currículos para um único sistema. Se houver apenas um currículo, o grau é 3, se houver mais de um currículo, o grau é 0 , não havendo grau 1 ou 2 para essa característica (JONNAERT; ETTAYEBI; DEFISE, 2010). Essa unicidade leva em 
consideração que a existência de mais de um currículo poderia fazer com que dentro do mesmo sistema educacional houvesse uma contradição entre os objetivos pretendidos.

O grau de participação (ser consensual) do currículo é definido através do número de atores da educação que participaram do processo de elaboração, sendo atribuído grau 0 para quando não há participação dos atores da educação, grau 1 quando há menos de $50 \%$, grau 2 para quando há de $50 \%$ a $80 \%$ e grau 3 para quando há mais de $80 \%$ de participação (JONNAERT; ETTAYEBI; DEFISE, 2010).

O grau de univocidade (ser unívoco) corresponde à coerência que existe entre os elementos que constituem o currículo, suas finalidades e suas orientações, sendo atribuído grau 0 para quando não há coerência entre as finalidades e orientações do currículo; grau 1 para quando as finalidades e orientações são coerentes entre si, mas não aos elementos que constituem o currículo; grau 2 quando as finalidades e orientações são coerentes entre si e incoerentes apenas com alguns elementos que constituem o currículo; grau 3 quando as finalidades, orientações e elementos do currículo são totalmente coerentes entre si (JONNAERT; ETTAYEBI; DEFISE, 2010). O grau de univocidade demonstra se a proposta é coerente com aquilo que será levado à prática, pois os currículos podem ser construídos com o objetivo de serem adaptados ao contexto, mas podem apresentar-se na forma de programas de ensino que não permitem essa adaptação.

O grau de adaptabilidade (ser flexível) refere-se a quanto o currículo pode adequar-se às evoluções das necessidades apresentadas no processo educacional, ou seja, sua flexibilidade. É atribuído grau 0 a um currículo totalmente inflexível, grau 1 ao que permite flexibilização de poucos elementos que constituem o currículo, grau 2 ao que permite flexibilização de maioria dos elementos constitutivos, e grau 3 ao que permite flexibilidade total (JONNAERT; ETTAYEBI; DEFISE, 2010).

O grau de coerência interna se refere à sintonia existente entre os diferentes elementos internos que constituem o currículo, sendo atribuído grau 0 para quando não há coerência alguma entre esses elementos, grau 1 para quando poucos elementos são coerentes entre si, grau 2 para quando muitos elementos são coerentes, e grau 3 para quando todos são coerentes entre si (JONNAERT; ETTAYEBI; DEFISE, 2010). A coerência interna de um currículo refere-se ao conjunto que representa os aspectos a serem desenvolvidos pelos alunos. Tem-se uma coerência interna quando as competências buscam interagir entre si mesmas e com os eixos temáticos que as perpassam.

O grau de coerência externa se refere à sintonia entre os elementos constituintes do currículo e a demanda social. É atribuído grau 0 para quando essa coerência não existe nem em nível local e nem internacional; grau 1 para quando é parcial em nível local e não existe para nível internacional; grau 2 para quando é parcial para nível local e internacional; e grau 3 para quando há coerência total em nível local e internacional (JONNAERT; ETTAYEBI; DEFISE, 2010). Esse é um grau que se assemelha à univocidade, mas busca agora identificar se o currículo interage com o meio.

Devido a todos esses fatores, por mais que a avaliação de um perfil curricular seja por características separadas, todos os graus estão interligados entre si e buscam no currículo a formação integral, não focada somente em saberes isolados, mas aplicados e originados dentro de diferentes contextos. Para Jonnaert, Ettayebi e Defise (2010), um currículo que não atinja pelo menos grau 2 em pelo menos quatro das seis características apresentadas, é considerado um currículo de risco, isto é, não contribui para os processos de ensino e aprendizagem. 
Análise do currículo referência de Química ...

\section{Método de pesquisa}

O caminho para as respostas das perguntas em torno da problemática apresentada foi orientado por um estudo documental, desenvolvido em uma abordagem qualitativa, utilizando-se das técnicas de análise de conteúdos para apresentar os resultados. Levando em consideração as orientações de Kripka, Scheller e Bonotto (2015) sobre a pesquisa documental, de abordagem qualitativa, estudaram-se as fontes primárias, neste caso, os documentos oficiais que tratam diretamente do currículo, em nível nacional e estadual. A análise dos dados foi realizada utilizando-se dos procedimentos da análise de conteúdo, por ter como foco a compreensão dos significados e a coerência da proposta curricular expressa nos documentos oficiais. Seguiram-se os passos sugeridos por Franco (2005), fazendo uma pré-análise dos dados, onde a primeira etapa consistiu na escolha dos documentos, na formulação dos objetivos e na definição dos indicadores que fundamentaram a interpretação das informações. Os documentos oficiais escolhidos foram as DCN da educação básica, os PCNEM da área de ciências da natureza e o Currículo de Referência da Rede Estadual de Educação de Goiás, mais especificamente, o currículo da área de Química. Para fundamentar as análises documentais, buscando dar significados aos discursos explícitos e implícitos nos documentos, procurou-se referenciar em estudos de Jonnaert, Ettayebi e Defise (2010), Libâneo (2011), Ribeiro Júnior (2013), entre outros.

A partir do estudo do referencial teórico e dos documentos, definimos, a priori, três categorias para a análise dos dados: interdisciplinaridade, contextualização e flexibilização. Tanto o referencial teórico, quanto os documentos oficiais indicaram que um currículo precisa ter as três características como base. Neste caso, considerando as ideias de Bardin (1977), o critério de categorização foi o semântico, por tentar compreender a coerência interna do discurso expresso nas DCN e PNCEM e até que ponto o Currículo Referência de Química da Rede de Educação de Goiás é flexível e permite um trabalho interdisciplinar e contextualizado na prática docente.

Para facilitar a análise das categorias, elaborou-se o quadro 1, dos eixos temáticos do Currículo Referência de Química, agrupando-os em eixos contextualizados e não contextualizados, comparando-os com a proposta das DCN. Procedimento semelhante também foi adotado na comparação do Currículo Referência de Química com os PCNEM, abordando no quadro 2 as habilidades definidas nos PCNEM e as expectativas de aprendizagem definidas no Currículo de Referência de Química. A partir da análise comparativa descrita, buscou-se identificar o perfil curricular de química da Rede Estadual de Educação de Goiás. O perfil foi traçado a partir de critérios discutidos por Jonnaert, Ettayebi e Defise (2010), levando em consideração aspectos gerais do currículo, como estrutura organizacional, contexto de elaboração e as análises com base nas DCN e PCNEM.

\section{Resultados e discussão}

O documento Currículo Referência da Rede Estadual de Educação de Goiás: versão experimental, publicado pela SEDUCE (GOIÁS, 2012), parece ser uma proposta que visa uma verdadeira melhoria da qualidade de ensino e da aprendizagem. Em termos de elaboração, o documento se apresenta como uma proposta discutida democraticamente com os diversos segmentos educacionais.Porém, ao avançar com as análises sobre o currículo, percebem-se con- 
tradições entre a proposta e as estruturas que contém os conteúdos e expectativas de aprendizagem. As críticas de Libâneo (2011) são direcionadas a essas estruturas que viriam a ser definidas como bimestralizações. Há menções à proposta que visam a desfragmentação e reformulação do currículo, porém, a maior parte das ideias apresentadas não condiz com a forma como ele será levado à prática, parecendo se tratar de um programa de ensino inflexível. Por mais que o documento cite em vários momentos que se baseia nos parâmetros curriculares nacionais (PCN) e PCNEM, pouco consegue fazer jus a eles, principalmente no que se trata da contextualização. Além disso, o Currículo Referência ainda se baseia na matriz do Exame Nacional do Ensino Médio (ENEM) e nas matrizes do Sistema de Avaliação da Educação Básica (SAEB).

Após a leitura e interpretação do Currículo Referência, observa-se que a bimestralização apresenta: estrutura bimestral: na forma de etapas anuais, sendo quatro bimestres por ano, a serem cumpridas em um período pré-determinado; etapas e modalidade de ensino: se é $1^{\circ}, 2^{\circ}, 3^{\circ}, 4^{\circ} \ldots$ e se é Ensino Fundamental ou Médio; expectativas de aprendizagem: correspondem às competências a serem desenvolvidas pelos alunos com o ensino dos conteúdos listados; eixo temático: expressa um grande bloco de conhecimentos que busca ligação com um determinado contexto; conteúdos: compreendem os conteúdos específicos a serem ensinados para desenvolvimento das competências listadas.

O currículo, em todo o seu corpo, usa esse modelo para todos os componentes curriculares do Ensino Fundamental e Médio. O documento não apresenta propostas de metodologias e avaliações, e, por isso, induz o professor a uma prática rotineira, ou seja, apenas ensinar os conteúdos apresentados. Está dividido de acordo com as quatro grandes áreas do conhecimento: Linguagens, Matemática, Ciências Humanas e Ciências da Natureza. No início do tópico de cada uma das áreas, há uma pequena introdução baseada principalmente nos PCNEM. Em cada tópico estão apresentados os subtópicos, que correspondem a cada componente curricular e, em seguida, aparecem as respectivas bimestralizações.

\section{O currículo de Química e as DCN}

O Currículo de Química apresenta uma lista de conteúdos a serem ensinados e competências estabelecidas, independentemente do contexto em que será praticado, sendo, portanto, um programa de ensino, conforme definição de Jonnaert, Ettayebi e Defise (2010). Esses conteúdos são delimitados por bimestre, como se a bimestralização fosse pronta e acabada, inviabilizando alterações ou possibilidade de transitar conteúdos de um bimestre para outro, demonstrando a negação do significado de artefato cultural, conforme Ribeiro Júnior (2013), passando a ter o significado de um objeto que se apresenta impossibilitado de outras significações.

O Currículo Referência de Química, mesmo que apresente objetivos que visem a interdisciplinaridade, transversalidade e contextualização, apresenta-se contraditório quanto às bimestralizações. O Quadro 1 apresenta 19 eixos temáticos do currículo, os quais foram divididos entre aqueles que se apresentam contextualizados e aqueles não contextualizados. 
Quadro 1. Eixos temáticos do Currículo Referência

\begin{tabular}{|c|c|}
\hline 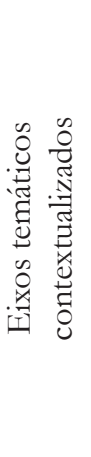 & $\begin{array}{l}\text { a. Química, Tecnologia, Sociedade e Meio Ambiente } \\
\text { b. Comportamento químico das substâncias - Ácidos e bases, Perturbações na hidrosfera } \\
\text { produzidas por ação humana: } \\
\text { c. Comportamento químico das substâncias - Sais e óxidos, Perturbações na atmosfera } \\
\text { produzidas por ação humana: } \\
\text { d. Controle da rapidez das transformações no dia a dia } \\
\text { e. Química Orgânica - Os materiais fósseis e seus usos } \\
\text { f. Funções Orgânicas e Produtos Químicos de Uso Cotidiano } \\
\text { g. Produção e Propriedade de Materiais Orgânicos de uso Cotidiano } \\
\text { h. Ciclos biogeoquímicos e suas relações com a biosfera - Biomoléculas e Polímeros } \\
\text { i. Energia nuclear: benefícios e impactos Ambientais }\end{array}$ \\
\hline 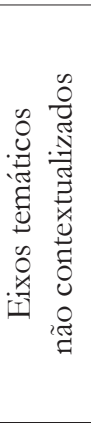 & $\begin{array}{l}\text { j. A linguagem da química - Primeiros modelos de constituição da matéria } \\
\text { k. Modelagem quântica, ligações químicas e propriedades dos materiais } \\
\text { 1. Interações intermoleculares e propriedades físicas e químicas das substâncias } \\
\text { m. Relações quantitativas de massa em química } \\
\text { n. Sistemas Aquosos -Misturas multicomponentes } \\
\text { o. Aspectos quantitativos em Sistemas Aquosos Misturas multicomponentes } \\
\text { p. Relações quantitativas envolvidas nas Transformações químicas: } \\
\text { q. Produção e consumo de energia térmica nas transformações químicas } \\
\text { r. Estado de equilíbrio Químico } \\
\text { s. Produção e consumo de Energia elétrica nas transformações químicas }\end{array}$ \\
\hline
\end{tabular}

Fonte: adaptado de Goiás (2012).

Os eixos temáticos contextualizados apresentam uma abertura para integração de outras áreas, como é observado no eixo A, por exemplo, que, ao citar os termos Tecnologia, Sociedade e Meio Ambiente, permite demonstrar que não se trata somente de conceitos químicos, mas sim da importância destes para o desenvolvimento das tecnologias, para a preservação do meio ambiente e para manter o bem-estar social. Diferentemente do eixo A, no eixo J, percebe-se o quanto a temática está focada somente na Química, não abrindo margem para conexão com outras áreas. Esse eixo foge ao contexto e permite uma mínima flexibilidade, pois é definitivo e objetivo ao que se propõe. Dessa forma, as análises demonstraram que nove dos eixos temáticos são contextualizados, enquanto os outros dez restringem-se ao conteúdo. Os nove eixos que oferecem possibilidades para contextualização do currículo apresentam uma integração do conceito ao contexto. Os outros dez eixos, que não são contextualizados, apresentam-se focados somente no ensino dos conceitos específicos de Química, sendo que deveriam perpassar os conhecimentos sobre uma mesma problemática. Isso mostra o quanto a contextualização é necessária para assegurar a transversalidade proposta pelas DCN, ficando a mesma explícita quando há associação dos conceitos químicos ao cotidiano, aos impactos ambientais, às ações humanas e ao dia a dia, como é tratado em nove eixos temáticos. 


\section{O currículo de Química e os PCNEM}

As expectativas de aprendizagem representam as competências que serão desenvolvidas pelos estudantes com o ensino dos conteúdos e, portanto, devem estar alinhadas com os eixos temáticos. Para análise das expectativas de aprendizagem, utilizaram-se os PCNEM de Ciências da Natureza, especificamente a parte referente à Química. Este documento traz três grandes domínios que representam as competências a serem desenvolvidas pelos estudantes, sendo que cada domínio é constituído por um conjunto de habilidades. O primeiro domínio é o da Representação e Comunicação, e foca no desenvolvimento de competências ligadas ao domínio da linguagem química, bem como sua representação através da matemática, símbolos, discursos e outros. O segundo domínio é o da Investigação e Compreensão, e foca no desenvolvimento de competências ligadas ao domínio dos conceitos, símbolos e cálculos químicos para estabelecer lógicas de investigação de problemáticas do próprio contexto da Química. O terceiro domínio é o da Contextualização sociocultural, e foca no reconhecimento da relação entre a Química e os diferentes contextos. É possível perceber nos PCNEM que existem nos três domínios a preocupação com a interdisciplinaridade, principalmente quando evoca o uso da matemática, da escrita, da tecnologia e outros.

A análise aqui realizada buscou verificar como os três domínios perpassam as expectativas de aprendizagem do currículo de química, fazendo-se uma comparação entre as competências estabelecidas. A análise levou em consideração as habilidades que estão relacionadas com cada domínio, sendo este um conjunto único de competências que correspondem a um conjunto de expectativas de aprendizagem, apresentados no Quadro 2.

Quadro 2. Comparação do currículo com os PCNEM de Química

\begin{tabular}{|l|l|l|}
\hline \multicolumn{1}{|c|}{$\begin{array}{c}\text { Domínios dos } \\
\text { PCNEM }\end{array}$} & \multicolumn{1}{|c|}{$\begin{array}{c}\text { Habilidades dos } \\
\text { PCNEM }\end{array}$} & \multicolumn{1}{c|}{$\begin{array}{c}\text { Expectativas de aprendizagem } \\
\text { do currículo }\end{array}$} \\
\hline $\begin{array}{l}\text { Representação e } \\
\text { comunicação }\end{array}$ & $\begin{array}{l}\mathrm{H} 1, \mathrm{H} 2, \mathrm{H} 3, \mathrm{H} 4, \mathrm{H} 5, \\
\mathrm{H} 6\end{array}$ & $\begin{array}{l}\mathrm{E} 3 \text { a E82, com exceção de: E10, E11, E14, E22, E25, } \\
\mathrm{E} 26, \mathrm{E} 37, \mathrm{E} 38, \mathrm{E} 39, \mathrm{E} 48, \mathrm{E} 58, \mathrm{E} 64, \mathrm{E} 65, \mathrm{E} 74, \mathrm{E} 75\end{array}$ \\
\hline $\begin{array}{l}\text { Investigação e } \\
\text { compreensão }\end{array}$ & $\begin{array}{l}\mathrm{H} 7, \mathrm{H} 8, \mathrm{H} 9, \mathrm{H} 10, \\
\mathrm{H} 11, \mathrm{H} 12, \mathrm{H} 13\end{array}$ & $\mathrm{E} 1$ a E82 \\
\hline $\begin{array}{l}\text { Contextualização } \\
\text { sócio-cultural }\end{array}$ & $\mathrm{H} 14, \mathrm{H} 15, \mathrm{H} 16, \mathrm{H} 17$ & $\begin{array}{l}\mathrm{E} 1, \mathrm{E} 2, \mathrm{E} 3, \mathrm{E} 27, \mathrm{E} 28, \mathrm{E} 31, \mathrm{E} 33, \mathrm{E} 46, \mathrm{E} 64, \mathrm{E} 65, \mathrm{E} 66, \\
\mathrm{E} 70, \mathrm{E} 74, \mathrm{E} 75, \mathrm{E} 77, \mathrm{E} 78, \mathrm{E} 79, \mathrm{E} 81, \mathrm{E} 82\end{array}$ \\
\hline
\end{tabular}

Fonte: adaptado de Goiás (2012) e Brasil (1999).

Em relação ao Quadro 2 pode-se afirmar que o currículo de química apresenta-se coerente com os PCNEM, mas não incorpora a ideia da interdisciplinaridade e contextualização defendida pelo mesmo. Das 82 (oitenta e duas) expectativas de aprendizagem somente 13 (treze) perpassam os três domínios, sendo E3, E27, E28, E31, E33, E46, E66, E70, E77, E78, E79, E81 e E82. Dessas expectativas, 12 (doze) fazem parte dos eixos temáticos que dão margem à contextualização, sendo esta a característica que as tornam competências que buscam a formação integral. Três delas são apresentados como exemplo do quanto suas essências estão de acordo com os documentos curriculares: 
E3 - Compreender a Quimica como uma ciência baseada nos eixos teórico, representacional e fenomenológico.

E46 - Interpretar os coeficientes estequiométricos de uma equação aplicando a exemplos importantes da indústria ou do dia a dia contrapondo a processos físicos.

E82 - Perceber os maiores e os menores perigos das emissões radioativas para os seres vivos.

As expectativas E3, E46 e E82 apresentam-se de forma a abranger os conceitos químicos ligados a outras áreas do conhecimento e a um contexto em específico. O contexto na E3 aparece na menção ao eixo fenomenológico, que se relaciona aos fenômenos sociais e naturais, enquanto em E46, faz-se menção à importância na indústria e no dia a dia; e, em E82, a menção é feita aos perigos para seres vivos. As três expectativas dão margem de abertura para buscar a compreensão do contexto em outras áreas do conhecimento. E3 permite a relação entre as Ciências Naturais e Humanas. E46 permite a relação entre Química e Física, e, E82 relaciona Química, Física e Biologia. Assim, é possível perceber que além dessas áreas envolvidas fica evidente que são possíveis abordagens mais amplas, já que os contextos envolvidos permitem tal ação.

As expectativas E7, E41 e E60 dão margem somente para a simples memorização de conceitos e fórmulas. Utilizou-se aqui, como exemplo, essas três expectativas que representam a forma engessada focada somente no conteúdo isolado:

E7 - Interpretar graficamente a mudança de estado físico de uma substância pura e de misturas.

E41 - Calcular e interpretar as principais formas de expressão da concentração: concentração comum $(\mathrm{g} / \mathrm{L})$, quantidade de matéria (mol/L) e porcentagem.

$\mathbf{E 6 0}$ - Reconhecer o agente redutor e oxidante em uma reação de óxido redução por meio do cálculo do número de oxidação (NOX) dos elementos.

Nas expectativas acima, a única margem de contextualização oferecida é restrita aos conceitos apresentados, não havendo relação com algum contexto que não seja o da Química. Isso sugere ao professor que o estudante deva desenvolver somente aquilo que está especificado, ou seja, saber interpretar graficamente a mudança de estado físico pode ser simplesmente uma exemplificação genérica como muitas vezes os livros didáticos apresentam. A E7 equivale dizer que não é obrigatório levar em consideração a natureza da substância, nem onde ela é utilizada e encontrada.

O desenvolvimento de uma competência genérica pode levar o estudante a crer que o conhecimento é tão somente para ser aprovado no vestibular, sendo isso "[...] consequência do conteudismo curricular a-histórico e centrado em uma forma de organização que faz sentido a quem já sabe química, mas revela-se pouco adequada aos que estão sendo iniciados a esta ciência" (RIBEIRO JÚNIOR, 2013, p. 67), pois assim demonstra não apresentar sentido para a vida cotidiana. Esse é um problema ocasionado pela falta de contextualização e que se agrava quando a Química se restringe a si mesma, sem levar em consideração as problemáticas que perpassam outras áreas do conhecimento. $\mathrm{O}$ aspecto que chamou muita atenção nessas análises foi o fato de todas as expectativas se encaixarem, de alguma forma, no domínio da investiga- 
ção e compreensão, que é aquele necessário para estabelecer as lógicas empíricas, formal e o raciocínio proporcional conforme os PCNEM (BRASIL, 1999).

No domínio da representação e comunicação, quase todas as expectativas se encaixaram, já no domínio da contextualização sociocultural foram poucas. Trindade (2008) afirma que a contextualização cria interfaces com outras áreas do conhecimento, sendo perceptível no currículo analisado que a falta de um contexto associado aos conceitos cria uma barreira para o trabalho interdisciplinar. Essa barreira pode criar obstáculos que não permitam aos conteúdos se ligarem ao contexto em questão, restringindo seus significados para a vida real, uma vez que a "[...] educação por competências começa a ser construída quando a escola assume que conteúdos disciplinares devem fazer, antes de tudo, sentido para os alunos" (CARDOSO; HORA, 2013, p. 3).

\section{O currículo de Química e o perfil curricular de Jonnaert, Ettayebi e Defise (2010)}

O Currículo Referência do Estado de Goiás é único, ou seja, apenas um documento curricular norteia o ensino médio no que concerne à Química, o que caracteriza o grau 3 de unicidade, conforme o que coloca Jonnaert, Ettaeyebi e Defise (2010). Essa é uma característica do currículo que permite criar um alinhamento entre todas as escolas, levando-as a trabalharem em torno de um único objetivo que culmina para um sistema educacional que oferece as mesmas oportunidades de estudo a todos os alunos.

No Brasil, essa ideia de unicidade vem sendo corroborada pela recente Base Nacional Comum Curricular (BNCC) (BRASIL, 2015), que tem ganhado espaço para esse tipo de discussão. A existência de uma base comum pode garantir aquilo que está nas DCN, de forma que os conhecimentos possam ser abordados em diferentes contextos regionais. Isso cria um alinhamento entre todas as Unidades Federativas, já que ultimamente cada uma tem criado seus próprios currículos com critérios distintos e, às vezes, até contrários ao que dizem os documentos curriculares.

$\mathrm{Na}$ análise do Currículo Referência, percebe-se que há possibilidade de alinhamento do currículo dentro do Sistema Educacional Goiano. No entanto, o documento está desalinhado em relação aos PCNEM e DCN, que são documentos norteadores em nível nacional. Jonnaert, Ettaeyebi e Defise (2010) não definem um grau intermediário entre 0 e 3 para a unicidade e apontam a avaliação do perfil para o sistema a que o currículo atende. Faz-se, assim, necessária uma análise à parte quanto a esse critério quando se considera outro contexto mais amplo, que será retomado quando for analisado o critério de coerência externa.

Um currículo precisa ser um consenso entre seus atores, já que eles são os responsáveis por levarem-no à prática. Consideram-se, aqui, atores da educação os profissionais docentes e os educandos (JONNAERT; ETTTAEYEBI; DEFISE, 2010). Estes devem participar do processo de construção do currículo, pois "ninguém mais do que os participantes da atividade escolar em seus diferentes segmentos, conhece a sua realidade e, portanto, está mais habilitado para tomar decisões a respeito do currículo que vai levar à prática” (BRASIL, 2013, p. 183). O professor é antes de tudo aquele que reflete sua prática, planeja suas aulas, executa-as e avalia todo o processo. Os estudantes, por sua vez, têm seu papel como sujeitos aprendizes e construtores do conhecimento junto aos seus professores. 
Segundo dados da própria SEDUCE, em 2012 a rede estadual contava com 46.860 professores atuando no ensino fundamental e no ensino médio (GOIÁS, 2016). O próprio Currículo Referência deixa bem claro que participaram do processo de elaboração pouco mais de quatro mil professores no ano de 2012 (GOIÁS, 2012), não informando se houve participação de estudantes. Portanto, menos de $10 \%$ dos professores da Rede Estadual de Educação de Goiás participaram da construção do Currículo Referência para a própria Rede. O currículo deve ser fruto de um processo de reflexão e de discussão desses atores da educação responsáveis por levar em consideração o contexto no qual se encontram inseridos. Dessa forma, avaliou-se a participação dos atores da educação com grau 1, pois não participaram pelo menos $50 \%$ dos mesmos, conforme critério de Jonnaert, Ettaeyebi e Defise (2010).

O texto de apresentação da área de Ciências da Natureza no Currículo Referência demonstra em alguns fragmentos seus objetivos principais da seguinte forma:

Os conhecimentos de Biologia, Física e Química devem ser tratados de forma integrada ao longo do ensino fundamental. No ensino médio, essa integração continua por meio da interdisciplinaridade que inúmeros conteúdos implicam. [...] A seleção dos conteúdos de cada eixo temático, a construção do planejamento das aulas, e a escolha de atividades se pautam pelas expectativas de aprendizagem. Pois, a proposta é ensinar com foco na aprendizagem e não na estrutura dos conteúdos (GOIÁS, 2012, p. 330-331).

O trecho destaca duas ideias contraditórias. Primeiro, cita que os conteúdos são integrados pela interdisciplinaridade que implicam, e, ao final do fragmento, diz que o importante não é ensinar com base na estrutura dos conteúdos. Essa interdisciplinaridade que se propõe não está ligada aos conteúdos, e sim às expectativas de aprendizagem que também apresentam restrições e deficiências em relação às suas estruturas. Cita a interdisciplinaridade como forma de dar sequência a uma integração, mas, as análises com base nos PCNEM e DCN demonstraram que o currículo não é muito interdisciplinar e ainda pouco contextualizado.

Ressalta-se aqui a crítica de Fazenda (2008) quando afirma que a interdisciplinaridade não se dá por simples integração dos conteúdos e observa que o Currículo Referência se assemelha muito mais a uma grade curricular onde apenas os conteúdos foram agrupados sem ao menos criar condições para uma abordagem interdisciplinar. Essa abordagem deveria ocorrer por meio de condições que permitem a transferência de métodos de uma disciplina para outra, conforme afirma as DCN (BRASIL, 2013). Porém, Libâneo (2011) aponta que o documento não apresenta suporte metodológico, ficando inviável a existência de tal transferência. Além disso, os conteúdos e expectativas de aprendizagem encontram-se selecionados e bimestralizados, deixando o professor impossibilitado de selecionar um conteúdo ou expectativas fora do respectivo bimestre. Essa inflexibilidade prejudica uma possível integração entre conteúdos da Química, Física e Biologia que permitiria um trabalho interdisciplinar.

Afirma-se, assim, que a flexibilidade do currículo analisado ocorre apenas dentro de um mesmo bimestre, quando o professor pode definir quais expectativas e conteúdos serão trabalhados primeiro e por último, não havendo autonomia para transição, alteração ou incorporação de bimestre e de etapa anual. Jonnaert, Ettayebi e Defise (2010) defendem a flexibilidade de um currículo como essencial para que possa haver a adaptação ao contexto, maior 
participação dos atores da educação e para que o conhecimento seja uma unidade e não saberes fragmentados. Essa característica permite que o currículo possa ser mais contextualizado e mais interdisciplinar, englobando eixos temáticos conforme as necessidades apresentadas, buscando o desenvolvimento de competências atuacionistas e não somente curriculares como apresenta um programa de ensino.

Dessa forma, o currículo permite que poucos elementos sejam adaptados, e suas finalidades não estão totalmente coerentes com os elementos que o constituem, pois há contradições. Vê-se, assim, que a flexibilidade e coerência do currículo, com relação às suas finalidades, são fragilidades que vinham sendo demonstradas quando se analisou o seu alinhamento às DCN e aos PCNEM. Atribuímos o grau 1 para univocidade, já que as orientações e finalidades estão coerentes entre si mas totalmente contraditórias às bimestralizações e, atribuímos o grau 1 para adaptabilidade uma vez que só podem ser feitas adaptações dentro de um mesmo bimestre, sendo essas adaptações somente de inversão de posição, pois o currículo não apresenta margem para incorporar ideias e nem para transitar expectativas de aprendizagem. Identificou-se que há boa coerência entre os conteúdos e as expectativas dispostas num mesmo bimestre, porém, existem expectativas que enquadram conteúdos além do seu referido bimestre ou mesmo da etapa anual, permitindo que sejam desenvolvidas de forma parcial e não sendo retomadas posteriormente pela pouca flexibilidade oferecida. A incoerência quanto aos elementos internos se faz presente entre eixos temáticos e expectativas de aprendizagem, pois quase metade desses eixos oferecem possibilidades de contextualização sociocultural, enquanto que apenas 19 (dezenove) das 82 (oitenta e duas) expectativas de aprendizagem são de fato contextualizadas.

Atribuiu-se grau 2 para coerência interna, considerando que boa parte dos elementos são coerentes entre si. Ribeiro Júnior (2013) chamam a atenção para os problemas causados pelo conteudismo escolar, tornando os conceitos mais distantes de contextos cada vez mais amplos. É a forte influência desse conteudismo que faz a coerência interna do Currículo Referência ser melhor que os demais aspectos, e, por outro lado, quase nenhuma coerência externa é identificada, pois esta é perdida quando os eixos temáticos não fazem jus ao que parecem propor.

As análises realizadas anteriormente demonstraram que um dos grandes problemas do currículo é a falta de interação com a realidade, principalmente em nível local, podendo haver fragilidades quando se considera uma esfera mais ampla. Normalmente, os estudantes podem apresentar dificuldades em compreender a Química dentro de seu contexto, e quando se considera contextos mais amplos, eles podem ser levados a pensar que a Química está mais distante ainda. Pode-se pensar no exemplo do funcionamento de uma plataforma petrolífera ou numa refinaria, que considerando o contexto regional goiano é algo distante. Esse exemplo se encaixaria num contexto nacional. Compreender o contexto de uma refinaria de petróleo sem antes compreender o petróleo num contexto mais próximo, pode se apresentar como uma problemática cuja solução é menos acessível ao estudante. Os PCNEM trazem essa condição quando afirmam que as Ciências da Natureza precisam estar integradas às Ciências Humanas para que se possa compreender e solucionar a problemática socioambiental (BRASIL, 1999).

O que está por trás de uma refinaria não é somente a destilação fracionada de petróleo, mas aspectos ligados à poluição, ao consumo de gasolina e diesel, preços de veículos motorizados, construção de postos de combustível, transporte de combustível, etc. Em suma, existem fatos de um contexto mais próximo que permitem a compreensão de um contexto mais distante. $\mathrm{O}$ currículo analisado não atende as demandas locais por se apresentar pouco contextualizado e 
inflexibilizado e, por isso, está parcialmente em sintonia com essa realidade. O contexto local faz parte de um contexto muito mais amplo, com diversas outras problemáticas que deveriam ser levadas em consideração. Afirma-se, então, que esse currículo engloba poucos elementos do contexto regional, distanciando-se mais dos contextos nacional e internacional. Por isso, atribuiu-se o grau 1 para coerência externa, conforme define Jonnaert, Ettayebi e Defise (2010). O Quadro 3 apresenta a síntese das análises realizadas acima, em relação às características do currículo, propostas por Jonnaert, Ettayebi e Defise (2010).

Quadro 3. Resumo dos graus atribuídos para o currículo analisado

\begin{tabular}{|l|c|}
\hline Características analisadas & Grau atribuído ao Currículo Referência \\
\hline Unicidade & 3 \\
\hline Participação & 1 \\
\hline Univocidade & 1 \\
\hline Adaptabilidade & 1 \\
\hline Coerência interna & 2 \\
\hline Coerência externa & 1 \\
\hline
\end{tabular}

Fonte: elaborado pelos autores a partir de Jonnaert, Ettayebi e Defise (2010).

A participação de atores da educação, univocidade, adaptabilidade e coerência externa se mostraram como as maiores fragilidades, sendo que a falta de participação mostra uma proposta onde não houve discussão suficiente e adequada ao contexto. A falta de univocidade mostra a contradição curricular. A inflexibilidade não permite a ressignificação do currículo conforme suas necessidades e a falta de coerência externa é corroborada pela falta de contextualização, interdisciplinaridade e transversalidade. Um currículo para ter o mínimo de operacionalidade deve ter pelo menos grau 2, e consideram que um currículo é de risco quando metade das características não atingem tal valor (JONNAET; ETTAEYEBI; DEFISE, 2010). O currículo de Química analisado obteve 4 das características abaixo do mínimo de operacionalidade, como mostrado no quadro 3. Essas características vêm sendo defendidas como determinantes na construção de um currículo integral. Sendo assim, o perfil aqui traçado corresponde a um programa de ensino restrito ao ensino de conteúdos de forma isolada, sendo, portanto, característica marcante da fragmentação do saber e preocupação com o desenvolvimento de competências específicas distante do contexto sociocultural.

\section{Considerações finais}

A análise do Currículo Referência de Química permitiu identificar um desalinhamento entre este e os principais documentos norteadores do currículo em nível nacional, como as DCN e os PCNEM. Observa-se, inicialmente, um discurso que defende aspectos da interdisciplinaridade e contextualização, mas se perde quando se propõe bimestralizações a serem cumpridas em tempos pré-determinados, com delimitações de conteúdos e competências. Muitos problemas apresentados no currículo analisado haviam sidos alertados por Ribeiro Júnior (2013), 
que participaram do processo de elaboração desse documento e identificaram que os professores presentes nas discussões tinham posicionamentos críticos em relação à forma curricular tradicional, e, mesmo assim, insistiram em prescrever um programa de ensino pouco flexível.

Essa pesquisa corrobora os problemas citados pelos autores e ainda apresenta outros que dificultam o trabalho docente e a aprendizagem dos estudantes, tanto problemas advindos da elaboração do currículo, como da forma como se encontra para execução. Dentre esses problemas, identificou-se: a falta de participação de número expressivo de professores e alunos na construção do currículo; desalinhamentos aos contextos regional, nacional e internacional; contradições teóricas; pouca adaptabilidade internamente e quase nenhuma externamente; falta de suporte metodológico e interdisciplinaridade restrita a uma pequena quantidade de aspectos. Esses são problemas bastante relevantes para discussões curriculares futuras em prol da melhoria dos aspectos fragilizados e da construção de novos perfis curriculares por meio de tais discussões que devem ocorrer sempre em sintonia com o contexto social e cultural.

\section{Referências}

AMORIM, F.; SOUZA, C. P.; TRÓPIA, G. Interdisciplinaridade, contextualização e pesquisa-ação: influência de um curso de formação continuada de professores de ciências na prática docente. In: ENCONTRO NACIONAL DE PESQUISA EM EDUCAÇÃO EM CIÊNCIAS, 7., 2009, Florianópolis. Anais... Disponível em: <http://posgrad.fae.ufmg.br/ posgrad/viienpec/pdfs/836.pdf>. Acesso em: 6 mar. 2016.

BARDIN, J. L'ére logique. Paris: Robert Laffont, 1977.

BRASIL. Ministério da Educação. Diretrizes curriculares nacionais da educação básica. Brasília, 2013. Disponível em: < http://portal.mec.gov.br/docman/julho-2013-pdf/13677diretrizes-educacao-basica-2013-pdf/file>. Acesso em: 16 ago. 2018.

BRASIL. Ministério da Educação. Base Nacional Comum Curricular. Brasília, 2015. Disponível em: <http://historiadabncc.mec.gov.br/documentos/BNCC-

APRESENTACAO.pdf> Acesso em: 16 ago. 2018.

BRASIL. Ministério da Educação. Parâmetros curriculares nacionais: o ensino médio, parte III ciências da natureza, matemática e suas tecnologias. Brasília, [1999]. Disponível em: <http://portal.mec.gov.br/seb/arquivos/pdf/ciencian.pdf> Acesso em: 20 fev. 2016.

CARDOSO, M. C.; HORA, D. M. Competências e habilidades: alguns desafios para a formação de professores. In: JORNADA DO HISTEDBR, 11., 2013, Cascavel. Anais... Disponível em: <http://www.histedbr.fe.unicamp.br/acer_histedbr/jornada/jornada11/ artigos/7/simposio7.html>. Acesso em: 12 fev. 2016.

FAZENDA, I. Interdisciplinaridade-transdisciplinaridade: visões culturais e epistemológicas. In: FAZENDA, I. (Org.). O que é interdisciplinaridade? São Paulo: Cortez, 2008. p. 17-28.

FRANCO, M. L. P. B. Análise de conteúdo. 2. ed. Brasília: Liber Livro, 2005. 
GOIÁS. Secretaria de Estado da Educação. Currículo referência da rede estadual de educação de Goiás: versão experimental. Goiânia, 2012. Disponível em: <http://portal. seduc.go.gov.br/Documentos\%20Importantes/Diversos/CurriculoReferencia.pdf>. Acesso em: 17 jan. 2016.

GOIÁS. Secretaria de Estado da Educação, Cultura e Esporte. Goiás transparente. Goiânia, 2016. Disponível em: <http://www.transparencia.go.gov.br/portaldatransparencia/pessoal/ folha-de-pagamento>. Acesso em: 25 fev. 2016.

GOODSON, I. Currículo: teoria e história. 14. ed. Petrópolis: Vozes, 2013.

JONNAERT, P.; ETTTAYEBI, M.; DEFISE, R. Currículo e competências. Porto Alegre: Artmed, 2010.

KRIPKA, R. M. L.; SCHELLER, M.; BONOTTO, D. L. Pesquisa documental: considerações sobre conceitos e características na pesquisa qualitativa. In: CONGRESSO IBERO-AMERICANO EM INVESTIGAÇÃO QUALITATIVA, 4., 2015, Aracajú. Atas... Disponível em: <https://proceedings.ciaiq.org/index.php/ciaiq2015/article/view/252>. Acesso em: 12 nov. 2017.

LIBÂNEO, J. C. Considerações críticas sobre o documento "Diretrizes do pacto pela educação: reforma educacional goiana” - setembro de 2011. [Goiânia], 2011. Disponível em: <http://sintego.org.br/midias/banners/13122013082557.pdf>. Acesso em: 16 ago. 2018.

RIBEIRO JÚNIOR, R. M. Análise do contexto de produção do texto de um referencial curricular oficial de química para o ensino médio em Goiás. 2013. 1206 f. Dissertação (Mestrado em educação em Ciências e Matemática) - Universidade Federal de Goiás, Goiânia, 2013. Disponível em: < http://repositorio.bc.ufg.br/tede/handle/tede/3314>. Acesso em: 16 ago. 2018.

SILVA, M. A. História do currículo e currículo como construção histórico-cultural. In: CONGRESSO LUSO-BRASILEIRO DE HISTÓRIA DA EDUCAÇÃO, 6., 2006, Uberlândia. Anais... Disponível em: <http://titosena.faed.udesc.br/Arquivos/Artigos_ textos_historia/Curriculo.pdf>. Acesso em: 16 ago. 2018.

TRINDADE, D. F. Interdisciplinaridade: um novo olhar sobre as ciências. In: FAZENDA, I. (Org.). O que é interdisciplinaridade? São Paulo: Cortez, 2008. p. 65-84.

Artigo recebido em 17/07/2017. Aceito em 03/01/2018.

Contato: Instituto Federal Goiano, Campus Iporá, Iporá, GO,

76200-000, Brasil. 